\title{
Model Pengabdian Masyarakat Berbasis Kawasan
}

\author{
Fakhruddin \\ Institut Agama Islam Negeri (IAIN) Curup, Indonesia \\ fakhruddinzidan@gmail.com
}

\begin{abstract}
Research problems increase community empowerment through the process of human capital and physical capital in the area around the community. The research objective is to develop a model that is supported by the concept of theoretical development. This research focuses on "process" as a key success for improving people's welfare. The relationship between capital and empowerment improvement will be tested in this study by putting the empowerment process as a mediating variable to explain activities related activities. The data used are primary and secondary data. Primary data is collected using survey method techniques through questionnaires. Furthermore, it is described and analyzed using theory. The findings of the study show that the service model leads to an increase in community empowerment, where (1) the model consists of two stages of empowerment, and (2) a model which indicates that three stages of the activity process are needed. There is a correlation where the higher the empowerment process will be able to create community empowerment. Implementation of this model states that empowerment wants the development of human capital and physical capital, and it will be even better if empowerment is supported by the development of the capacity of the actors of empowerment.
\end{abstract}

Keywords: empowerment; capital; society, humans

\begin{abstract}
Abstrak
Masalah penelitian meningkatkan keberdayaan masyarakat melalui proses modal manusia dan modal fisik yang berada di kawasan sekitar masyarakat. Tujuan penelitian untuk mengembangkan model yang didukung oleh konsep pengembangan teoritik. Penelitian ini memfokuskan "proses" sebagai kunci keberhasilan untuk meningkatkan kesejahteraan masyarakat. Hubungan antara modal dan perbaikan keberdayaan akan diuji pada penelitian ini dengan meletakkan proses pemberdayaan sebagai variabel mediasi untuk menjelaskan aktivitas-aktivitas yang terkait. Data yang digunakan adalah data primer dan sekunder. Data primer dikumpulkan dengan menggunakan teknik metode survey melalui kuesioner. Selanjutnya, diuraikan dan dianalisis menggunakan teori.temuan penelitian menunjukkan model pengabdian yang mengarah pada peningkatan keberdayaan masyarakat, dimana (1) model yang terdiri dari dua tahapan untuk keberdayaan, dan ke (2) model yang menunjukkan bahwa untuk meningkatkan keberdayaan diperlukan tiga tahapan proses aktivitas. Terdapat korelasi dimana semakin tinggi proses pemberdayaan akan dapat menciptakan keberdayaan masyarakat. Implementasi model ini menyatakan bahwa pemberdayaan menginginkan
\end{abstract}

FOKUS : Jurnal Kajian Keislaman dan Kemasyarakatan Vol. 3, No. 2, 2018

P3M Sekolah Tinggi Agama Islam Negeri (STAIN) Curup - Bengkulu

Available online: http://journal.staincurup.ac.id/index.php/JF

p-ISSN 2548-334X, e-ISSN 2548-3358 
pengembangan modal manusia dan modal fisik, dan akan lebih baik lagi jika pemberdayaan didukung oleh pengembangan kemampuan pelaku pemberdayaan.

Kata Kunci: keberdayaan; modal; masyarakat; manusia

\section{PENDAHULUAN}

Pengabdian masyarakat adalah suatu kegiatan yang bertujuan membantu masyarakat tertentu dalam beberapa aktivitas tanpa mengharapkan imbalan dalam bentuk apapun. ${ }^{1}$ Secara umum program ini dirancang oleh perguruan tinggi untuk memberikan kontribusi nyata bagi masyarakat, khususnya dalam mengembangkan kesejahteraan dan kemajuan masyarakat. $^{2}$ Kegiatan Pengabdian Masyarakat merupakan salah satu bagian dari Tri Dharma Perguruan Tinggi.

Satu hal yang sangat menarik seperti apa yang digambarkan selama ini, yakni Islam memiliki karekteristik global, bisa diterima dalam setiap ruang dan waktu. Namun pada sisi yang lain, saat ia memasuki berbagai kawasan wilayah, karekteristik global seolah-olah hilang melebur ke dalam berbagai kekuatan lokal yang dimasukinya. ${ }^{3}$ Satu kecenderungan dimana biasa Islam mengadaptasi terhadap kepentingan mereka.

Studi kawasan merupakan kajian dapat menjelaskan situasi saat ini karena fokus materi kajianya tentang berbagai area mengenai kawasan manusia dan lingkup pranata yang ada di dalamnya. Mulai dari pertumbuhan, perkembangan, serta ciri-ciri karakteristik sosial budaya yang ada di dalamnya, termasuk juga faktor-fakor pendukung bagi munculnya berbagai ciri dan karakter serta pertumbuhan kebudayaan pada setiap kawasan Islam. ${ }^{4}$ Dengan demikian secara formal objek studinya harus meliputi aspek geografis, demografis, historis, bahasa,

\footnotetext{
${ }^{1}$ Sulistiyani, Kemitraan dan Model-Model Pemberdayaan. (Yogyakarta: Gaya Media, 2004), hlm.7. hlm.38

${ }^{2}$ Hikmat, Strategi Pemberdayaan Masyarakat, (Humaniora: Bandung, 2004),

${ }^{3}$ Ghozali, Structural Equation Modelling, Metode Alternatif dengan Partial Least Square PLS, (Badan Penerbit Undip. Indonesia, 2006).

${ }^{4}$ Ibid
} 
serta berbagai perkembangan sosial budaya, yang merupakan ciri-ciri umum dari keseluruhan perkembangan pada setiap kawasan budaya.

Penelitian ini mengkaji beberapa permasalahan yang berkaitan dengan pemetaan kawasan masyarakat Islam yang berpengaruh terhadap tingkat keberdayaan masyarakat dan merumuskan model pengabdian yang sesuai dengan peta kawasan. Penelitian ini bertujuan: Pertama, merumuskan studi kawasan pengabdian masyarakat STAIN Curup; Kedua, memetakan kawasan pengabdian masyarakat STAIN Curup; Ketiga, memformulasi model-model pengabdian masyarakat STAIN Curup.

Penelitian ini adalah Penelitian Pengembangan yang merupakan suatu usaha untuk mengembangkan suatu produk yang efektif untuk digunakan dalam sebuah institusi, dan bukan untuk menguji teori. Dengan langkah-langkah penelitian sebagai berikut: Pertama, mempelajari temuan penelitian yang berkaitan dengan model pengabdian yang akan dikembangkan; Kedua, mengembangkan Model Pengabdian berdasarkan temuan ini, bidang pengujian dalam pengaturan di mana ia akan digunakan akhirnya; ketiga, dan merevisinya untuk memperbaiki kekurangan yang ditemukan dalam tahap mengajukan pengujian.

Penelitian ini menggunakan teknik dan instrumen pengumpulan data yaitu: observasi, konsultasi ahli/pakar, pemerintah daerah dan tokoh masyarakat, dan penelusuran perpustakaan. Selanjutnya, dikembangkan menggunakan prosedur pengembangan Dick \& Carey, yaitu; Pertama, Tahap Analisis Kebutuhan terhadap produk yang ada (Model Pengabdian yang ada); Kedua, Tahap Desain Produk berdasarkan pemetaan terhadap kawasan yang ada (Pemetaan terhadap basis kawasan pengabdian masyarakat); Ketiga, Tahap Validasi dan Evaluasi; Keempat, Tahap Produk Akhir (produk akhir berupa model) menggunakan Desain Uji Coba Produk; Pravalidasi, Validasi Pakar, Uji Kesesuaian Kebutuhan. ${ }^{5}$

${ }^{5}$ Sulistiyani, Kemitraan dan Model-Model Pemberdayaan. (Yogyakarta: Gaya Media, 2004), hlm. 9. 


\section{PEMBAHASAN}

\section{Pengabdian Masyarakat dan Basis Kawasan Masyarakat}

Secara teori, penelitian ini merumuskan bahwa pengabdian masyarakat adalah suatu kegiatan yang bertujuan membantu masyarakat tertentu dalam beberapa aktivitas tanpa mengharapkan imbalan dalam bentuk apapun. Meliputi:

1. Menciptakan inovasi teknologi untuk mendorong pembangunan ekonomi Indonesia dengan melakukan komersialisasi hasil penelitian;

2. Memberikan solusi berdasarkan kajian akademik atas kebutuhan, tantangan, atau persoalan yang dihadapi masyarakat, baik secara langsung maupun tidak langsung;

3. Melakukan kegiatan yang mampu mengentaskan masyarakat tersisih (preferential option for the poor) pada semua strata, yaitu masyarakat yang tersisih secara ekonomi, politik, sosial, dan budaya;

4. Melakukan alih teknologi, ilmu, dan seni kepada masyarakat untuk pengembangan martabat manusia dan kelestarian sumber daya alam. ${ }^{6}$

Sedangkan pengertian basis kawasan masyarakat, berasal dari kata "kawasan" dari bahasa Jawa Kuno: kawaśan, yang berarti daerah waśa, dari bahasa Sanskerta: "memerintah" yang artinya daerah yang memiliki ciri khas tertentu atau berdasarkan pengelompokan fungsional kegiatan tertentu, seperti kawasan desa, kawasan kota, kawasan suburban, di dalamnya kawasan industri, kawasan perdagangan, dan kawasan rekreasi. ${ }^{7}$

Pemetaan kawasan masyarakat Islam mulai dari pertumbuhan, perkembangan, serta ciri-ciri karakteristik sosial budaya yang ada di dalamnya, termasuk juga faktor-fakor pendukung bagi munculnya berbagai ciri dan karakter serta pertumbuhan kebudayaan pada setiap

\footnotetext{
${ }^{6}$ Syabra,"Modal Sosial: Konsep dan aplikasi". Jurnal Masyarakat dan Budaya. Vol.5. No.1, 2003, hlm.1-5.

${ }^{7}$ Suharto, Membangun Masyarakat Memberdayakan Rakyat: Kajian Strategis Pembangunan Kesejahteraan Sosial dan Pekerjaan Sosial. (Bandung: Rafika Aditama, 2005), hlm.13.
} 
kawasan Islam. Dengan demikian secara formal objek studi kawasan masyarakat Islam harus meliputi aspek geografis, demografis, historis, bahasa, serta berbagai perkembangan sosial budaya, yang merupakan ciriciri umum dari keseluruhan perkembangan pada setiap kawasan budaya.

\section{Analisis terhadap Model Pengabdian Masyarakat STAIN Curup}

Mencermati model pengabdian masyarakat yang ada di STAIN Curup selama ini ditemukan: 1) pengabdian berdasarkan objek antara lain: pembinaan anak jalanan, narapidana anak, 2) pengabdian berdasarkan lembaga antara lain: sekolah, madrasah, pondok pesantren, majelis taklim, masjid; 3) pengabdian berbasis masalah antara lain: kemampuan imam dan khatib, kemiskinan buruh pecetak batu bata. ${ }^{8}$

Pengabdian Berbasis Disiplin Ilmu Pengabdi antara lain: peningkatan kemampuan bahasa Arab, akselerisasi kemampuan bahasa Inggris di Panti Asuhan. Pengabdian Berbasis PAR antara lain: PAR di Masyarakat, PAR di Pesantren, PAR di Madrasah.

Berdasarkan pemetaan kawasan pengembangan pengabdian yang dilakukan selama ini adalah;

1. Kawasan Masyarakat Desa, yaitu Kawasan Masyarakat Petani dan Buruh Petani, Kawasan Masyarakat Desa Agro Bisnis, Kawasan Masyarakat Desa Miskin, Kawasan Masyarakat Desa Terisolir, Kawasan Masyarakat Desa Rawan Kriminal.

2. Kawasan Masyarakat Kota Kecil, yaitu Kawasan Masyarakat Pedagang, Kawasan Masyarakat Miskin Kota ${ }^{9}$

\section{Pengembangan Model Pengabdian Berbasis Kawasan}

Setelah melalui proses tahapan penelitian, maka penelitian ini merumuskan model-model pengabdian berbasis kawasan: 


\section{Pengabdian Sosial Kultural Pemberdayaan Kawasan Masyarakat Desa}

Pendekatan sosio-kultural adalah salah satu pendekatan yang dilakukan sebagai upaya melakukan perubahan ke arah yang lebih baik, yaitu terciptanya keadilan dan kesejahteraan sosial bagi masyarakat dengan memperhatikan berbagai aspek yang mempengaruhinya. ${ }^{10} \mathrm{Di}$ samping pendekatan sosio-kultural ini, sering kali terjadi perubahan itu dilakukan dengan menggunakan pendekatan struktural, yaitu pendekatan dari atas ke bawah.

Ada beberapa tahapan yang seharusnya dilalui dalam melakukan pemberdayaan. Pertama, membantu masyarakat dalam menemukan masalahnya. Kedua, melakukan analisis (kajian) terhadap permasalahan tersebut secara mandiri (partisipatif). Kegiatan ini biasanya dilakukan dengan cara curah pendapat, membentuk kelompok-kelompok diskusi, dan mengadakan pertemuan warga secara periodik (terus menerus). Ketiga, menentukan skala prioritas masalah, dalam arti memilah dan memilih tiap masalah yang paling mendesak untuk diselesaikan. Keempat, mencari cara penyelesaian masalah yang sedang dihadapi, antara lain dengan pendekatan sosio-kultural yang ada dalam masyarakat. Kelima, melaksanakan tindakan nyata untuk menyelesaikan masalah yang sedang dihadapi. Keenam, mengevaluasi seluruh rangkaian dan proses pemberdayaan itu untuk dinilai sejauh mana keberhasilan dan kegagalannya. ${ }^{11}$

\section{Model Pembinaan Masyarakat Petani dan Buruh Tani Tradisional}

Sebutan Masyarakat Petani dan Buruh Tani Tradisional adalah petani atau buruh yang memanfaatkan sumber daya pertanian dengan peralatan tangkap tradisional, modal usaha yang kecil, dan organisasi penangkapan yang relatif sederhana. Dalam kehidupan sehari-hari, petani dan buruh

\footnotetext{
${ }^{10}$ Adi, Pemberdayaan, Pengembangan Masyarakat dan Intervensi Komunitas. (Jakarta: Lembaga Penerbit FEUI, 2003), hlm. 71.

${ }^{11}$ Sumodiningkrat, Pemberdayaan Masyarakat dan Jaring Pengaman Sosial, Jakarta:Gramedia, 1999), hlm. 34.
} 
Fakhruddin : Model Pengabdian Masyarakat Berbasis Kawasan ... | 125

tradisional lebih berorientasi pada pemenuhan kebutuhan sendiri (subsistence). ${ }^{12}$ Dalam arti hasil alokasi hasil tangkapan yang dijual lebih banyak dipergunakan untuk memenuhi kebutuhan pokok sehari-hari, khususnya pangan, dan bukan diinvestasikan kembali untuk pengembangan skala usaha. ${ }^{13}$

Dalam rangka memperbaiki taraf hidup dan memberi peluang kepada petani dan buruh tradisional agar dapat melakukan mobilitas vertikal, paling tidak ada dua jalan yang bisa ditempuh. Pertama, adalah dengan cara mendorong pergeseran status petani dan buruh tradisional menjadi petani dan buruh modern. Kedua, dengan cara tetap membiarkan petani dan buruh tradisional dalam status "tradisional", tetapi memfasilitasi mereka agar lebih berdaya dan memiliki kemampuan penyangga ekonomi keluarga yang kenyal terhadap tekanan krisis. ${ }^{14}$

\section{Model Pemberdayaan Kawasan Masyarakat Home Industri Agro Bisnis}

Bagi warga masyarakat yang tinggal di desa atau daerah dengan sumber daya ekonomi yang mencukupi dan relatif bervariasi, sebetulnya di sana ada banyak kesempatan yang memungkinkan penduduk desa setempat menekuni bidang lain di luar pertanian. ${ }^{15}$ Cuma, sayangnya dalam kenyataan tidak semua kawasan masyarakat pertanian memiliki usaha untuk mencari pekerjaan di luar sektor perikanan.

Program ini bertujuan untuk meningkatkan kemampuan usaha menengah, usaha kecil dan tradisional dalam berusaha dalam jangka

\footnotetext{
${ }^{12}$ Sumodiningrat, Visi dan Misi Pembangunan Pertanian Berbasis Pemberdayaan, (Yogyakarta: IDEA, 2000), hlm. 93.

${ }^{13}$ Syabra, "Modal Sosial: Konsep dan aplikasi", Jurnal Masyarakat dan Budaya. Vol.5. N0.1, 2003, hlm.1-5.

${ }^{14}$ Tjokrowinoto, Pembangunan Dilema dan Tantangan, (Yogyakarta: Pustaka Pelajar, 2001), hlm. 92.

${ }^{15}$ Woodward, Industrial Organization: Theory and Practice, (Oxford University Press, Oxford, 1965), hlm.52.
} 
peningkatan pendapatan masyarakat, penciptaan lapangan kerja, dan meningkatkan efisiensi dan produktivitas pembangunan ekonomi.

\section{Model Pengelolaan Implementasi Ekosistem Kawasan Rawan Lingkungan}

Pengelolaan lingkungan adalah suatu bentuk kegiatan usaha yang dilakukan dalam rangka memperoleh manfaat lingkungan dan hasil lingkungan menurut peraturan perundang-undangan yang berlaku. Beberapa kegiatan yang mendukung arah dan tujuan pengelolaan lingkungan alam : Inventarisasi sumber daya lingkungan alam bertujuan untuk mengetahui dan mengevaluasi merencanakan pemanfaatan secara lestari. $^{16}$

Inventarisasi sumber daya lingkungan alam dilaksanakan secara periodik, hal ini disebabkan oleh adanya perubahan-perubahan oleh keadaan sumber daya lingkungan alamnya sendiri, baik karena faktor alami maupun faktor buatan. Penatagunaan sumber daya lingkungan alam bertujuan untuk menjamin kepastian kawasan sumber daya lingkungan alam tersebut dengan fungsinya, baik secara fisik di lapangan maupun secara hukum. ${ }^{17}$

\section{Model Sosial Kultural Kesadaran Hukum Kawasan Rawan Keamanan}

Pendekatan sosio-kultural adalah salah satu pendekatan yang dilakukan sebagai upaya melakukan perubahan ke arah yang lebih baik, yaitu terciptanya keadilan dan kesejahteraan sosial bagi masyarakat dengan memperhatikan berbagai aspek yang mempengaruhinya. ${ }^{18} \mathrm{Di}$

\footnotetext{
${ }^{16}$ Slamet, Pemberdayaan Masyarakat dalam Membetuk Pola Perilaku Manusia Pembangunan, Disunting oleh Ida Yustina dan Adjat Sudradjat. (Bogor: IPB Press, 2003), hlm.97.

${ }^{17}$ Simon, "Rethingking Empowerment", Journal of Progressive Human Service. Pirst Editor, 1990, hlm.32.

${ }^{18}$ Kartasasmita, Power and Empowermant: Sebuah Telaah Mengenal Konsep Pemberdayaan Masyarakat. (Jakarta: Badan Perencanaan Pembangunan Nasional, 1996), hlm.29.
} 
samping pendekatan sosio-kultural ini, sering kali terjadi perubahan itu dilakukan dengan menggunakan pendekatan struktural, yaitu pendekatan dari atas ke bawah.

Ada beberapa tahapan yang seharusnya dilalui dalam melakukan pemberdayaan. Pertama, membantu masyarakat dalam menemukan masalahnya. Kedua, melakukan analisis (kajian) terhadap permasalahan tersebut secara mandiri (partisipatif). Kegiatan ini biasanya dilakukan dengan cara curah pendapat, membentuk kelompok- kelompok diskusi, dan mengadakan pertemuan warga secara periodik (terus menerus). Ketiga, menentukan skala prioritas masalah, dalam arti memilah dan memilih tiap masalah yang paling mendesak untuk diselesaikan. K.eempat, mencari cara penyelesaian masalah yang sedang dihadapi, antara lain dengan pendekatan sosio-kultural yang ada dalam masyarakat. K.elima, melaksanakan tindakan nyata untuk menyelesaikan masalah yang sedang dihadapi. Keenam, mengevaluasi seluruh rangkaian dan proses pemberdayaan itu untuk dinilai sejauh mana keberhasilan dan kegagalannya. ${ }^{19}$

\section{Model Kesadaran Wisata Kawasan Masyarakat Rekreasi}

Dengan dibantu oleh tim ahli dan berbagai sudut pandang keilmuan (personal judgmenf) maka berbagai perencanaan program akan dapat diketahui kekuatan dan kelemahannya, sehingga apiikasinya akan dapat diefektifkan. ${ }^{20}$ Oleh karena itu, keterlibatan semua komponen di dalam pengembangan masyarakat dirasakan sebagai sesuatu yang penting di dalam kerangka membangun masyarakat seutuhnya.

\section{Model Pengembangan Kawasan Masyarakat Pedagang}

\footnotetext{
${ }^{19}$ DeLong, D.W. and Fahey, Diagnosing Cultural Barriers to Knowledge Management The academy of Management Executive, 2000, hlm. 73.

${ }^{20}$ Suharto, Membangun Masyarakat Memberdayakan Rakyat: Kajian Strategis Pembangunan Kesejahteraan Sosial dan Pekerjaan Sosial, (Bandung: Rafika Aditama, 2005), hlm. 32.
} 
Program ini bertujuan untuk meningkatkan kemampuan usaha menengah, usaha kecil dan tradisional dalam berusaha dalam jangka peningkatan pendapatan masyarakat, penciptaan lapangan kerja, dan meningkatkan efisiensi dan produktivitas pembangunan ekonomi.

\section{Model Pemberdayaan Masyarakat Miskin Perkotaan}

Kawasan miskin perkotaan yang merupakan akibat dari berbagai aktivitas yang kurang bertanggung jawab, juga akibat dari ketidakmerataan pembangunan suatu kota, merupakan penyebab utama terjadinya kantong-kantong kemiskinan kota. $^{21}$ Ini adalah salah satu masalah social yang sampai dengan saat ini sulit terpecahkan, dan nyaris mustahil dapat diselesaikan hanya dalam hitungan satu dua tahun.

Model Pemberdayan Masyarakat Miskin Perkotaan merupakan program pembangunan berdasar partisipasi masyarakat (community based development). Pelaksanaan program diarahkan untuk melakukan pemberdayaan kepada warga masyarakat kampung setempat, agar dapat meningkatkan kondisi sosial ekonomi dan lingkungannya secara mandiri/berkelanjutan. ${ }^{22}$

Program Rehabilitasi Sosial dirumuskan dan dilaksanakan dengan menggunakan pendekatan bottom up, di mana pada pelaksanaan kegiatan di lapangan, dilakukan atas inisiatif dan aspirasi dari masyarakat, mulai dari kegiatan perencanaan, pelaksanaan sampai dengan pengawasan pelaksanaan pembangunan. ${ }^{23}$ Masyarakat memiliki peran yang sangat penting dan dituntut untuk terlibat secara aktif dalam pelaksanaan program pembangunan ini, berhasil atau tidaknya pelaksanaan program ini ditentukan oleh partisipasi masyarakat itu sendiri.

\footnotetext{
${ }^{21}$ Tobing, Pendidikan dan Pertumbuhan Ekonomi, (Article on-line), 2005. Diakses dari http://www-theindone-sian-institute.org/janeducfile.htm.Internet.

${ }^{22}$ Jamasy, Keadilan, Pemberdayaan, \& Penanggulangan Kemiskinan, (Jakarta Selatan: Blantika, 2004), hlm.56.

${ }^{23}$ Chin,W.W, Marcolin,B.L dan Newsted,P.R. A Partial Least Squares Latent Variable Modeling Approach for Measuring Interaction Effects: Result from a Monte Carlo Simulation Study and Voice Mail Emotion/Adoption Study. Proceeding of the Seventeenth International Conference on Information System.16_18 December. Cleveland.Ohio. hlm.60.
} 


\section{PENUTUP}

Berdasarkan analisis penelitian yang telah dilakukan, maka dapat disimpulkan bahwa: Pertama, analisis terhadap model pelaksanaan pengabdian masyarakat STAIN Curup selama ini, memerlukan kesadaran kawasan. Kedua, pemetaan terhadap kawasan yang ada di wilayah sekitar STAIN Curup, mempertajam dan memperkuat daya pengabdian masyarakat STAIN Curup. Ketiga, Model Pengabdian Masyarakat Berbasis Kawasan menambah ragam model pengabdian masyarakat

\section{DAFTAR PUSTAKA}

Adi, I.R. 2003. Pemberdayaan, Pengembangan Masyarakat dan Intervensi Komunitas. Jakarta: Lembaga Penerbit FEUI.

Alchian, A. and Demsetz, H. 1973. The property rights paradigm, Journal of Economics History, 33, pp. 16-27.

AMW, Pranarka (ed). 1996, Pemberdayaan: Konsep, Kebijakan dan Implementasi. Jakarta: Center for Strategic and International Studies (CSIS).

Bandura, A. 1997. Social Learning Theory. Englewood Cliffs, NJ: Prentice Hall.

Chin,W.W, Marcolin, B.L dan Newsted,P.R. 1996. A Partial Least Squares Latent Variable Modeling Approach for Measuring Interaction Effects: Result from a Monte Carlo Simulation Study and Voice Mail Emotion/Adoption Study. Proceeding of the Seventeenth International Conference on Information System.16_18 December. Cleveland.Ohio

Coolis, D. J. 1991. A resource-based analysis of global competition: The case of the bearing industry. Strategic Management Journal.12. 4968.19

DeLong, D.W. and Fahey, L. 2000. Diagnosing Cultural Barriers to Knowledge Management.The academy of management Executive.

Drucker, P. 1969, The age of discontinuity: guidelines to our changing society. London: Heinemann. 
Eisenhardt, K. M., and Martin, J. A. 2000. 'Dynamic capabilities: What are they?' Strategic Management Journal, 32, 543-76.

Fahey, L., and Narayanan, V. K. 1986. Macroenvironmental Analysis for Strategic Management.West Publishing Company: St. Paul, MN.

Friedman.J. 1992. Empowerment, The Politics of Alternative Development Cambrige Blacwell

Fukuyama, 1995. Trust: The Social Virtues and the Creation of Prosperity. Free Press, ISBN 0-02-910976_0

Ghozali, I. 2001. Aplikasi Analisis Multivariate Dengan Program SPSS. Program Magister akuntansi, Program Magister Manajemen Undip.

Ghozali, I. 2006. Structural Equation Modelling, Metode alternatif Dengan Partial Least Square PLS, Badan Penerbit Undip. Indonesia

Gold, Michael, 1991: Strategic Control in the Decentralized Firm, Sloan Management Review, Winer

Hikmat, H. 2004. Strategi Pemberdayaan Masyarakat. Humaniora: Bandung.

Huseini, M. 1999. Mencermati Misteri Globalisasi: Menata Ulang Strategi Pemasaran Internasional Indonesia Melalui Pendekatan Resource-Based. Depok: Fisip Universitas Indonesia.

Hitt, M. A., Ireland. R. D., \& Hoskisson, R. E. 1999a. Strategic Management: Competitiveness and Globalization (3rd ed.). Cincinati: South-Western Publishing.

Hunt, S. D. 1997. Resource advantage theory: An evolutionary theory of competitive firm behavior. Journal of Economic Issues, Vol. 31(1), 59-75.

Jamasy, O. 2004. Keadilan, Pemberdayaan, \& Penanggulangan Kemiskinan. Jakarta Selatan: Blantika.

Kartasasmita, G. 1995. Ekonomi Rakyat: Memadukan Pertumbuhan dan Pemerataan. Jakarta: CIDES

Kartasasmita, G. 1996. Power and Empowermant: Sebuah Telaah Mengenal Konsep Pemberdayaan Masyarakat. Jakarta: Badan Perencanaan Pembangunan Nasional.

Lyles, MA and Salk, JE. 1996. "Knowledge Acqusition From Foreign Parents in International Joint Ventures : An Empirical Examination in The Hungarian Context". Journal of International Business Studies, 27, 5, 877-903.

Minttzberg, H. 1979. The Structure of organizaions, prentice-hall, New York, NY

Pranarka dan Vidhyandika, 1996, Pemberdayaan dalam Onny S.P 
Romer Paul,Endogenous Technological Change dalam Journal of Political Economy Shachs, J \& Lipton, D. 1990. Polland's economic reform, |Foregn Affairs, 69(3): 47-66

Simon, BL, 1990. Rethingking Empowerment, Journal of Progressive Human Service. Pirst Editor

Simon, H. 1993. Hutan Jati dan Kemakmuran.Problematika dan Strategi Pemecahannya. Yogyakarta: Aditya Media.

Slamet, M. 2003. Pemberdayaan Masyarakat. Dalam Membetuk Pola Perilaku Manusia Pembangunan. Disunting oleh Ida Yustina dan Adjat Sudradjat. Bogor: IPB Press.

Smith Adam,1976 An Inquiry into The Nature and Causes of The Wealth of Nations ; New York: Modern Library

Suharto, E. 2005. Membangun Masyarakat Memberdayakan Rakyat: Kajian Strategis Pembangunan Kesejahteraan Sosial dan Pekerjaan Sosial. Bandung: Rafika Aditama.

Suharto, E. \& Yuliani. 2005. "Analisis Jaringan Sosial: Menerapkan Metode Asesmen Cepat dan Partisipatif (MACPA) Pada Lembaga Sosial Lokal di Subang, Jawa Barat". (Article on-line).Didapat dari http://www.policy.hu/suharto/mak-Indo4.html.Internet; Diakses pada 28 Juli 2005.

Sulistiyani, A.T. 2004. Kemitraan dan Model-Model Pemberdayaan. Yogyakarta: Gaya Media.

Sumardjo. 1999. "Transformasi Model Penyuluhan Pertanian Menuju Pengembangan Kemandirian Petani: Kasus di Propinsi Jawa Barat". Disertasi Doktor. Bogor: Program Pascasarjana Institut Pertanian Bogor.

Sumodiningkrat, G, 1999. Pemberdayaan Masyarakat dan Jaring Pengaman Sosial, Gramedia. Jakarta

Sumodiningrat, G. 2000. Visi dan Misi Pembangunan Pertanian Berbasis Pemberdayaan. Yogyakarta: IDEA.

Syabra, R. 2003. "Modal Sosial, Konsep, dan Aplikasi". Jurnal Masyarakat dan Budaya. Vol.V. N0.1:1-5.

Timmons, JA. 1994. New Centure Creation. Burr Ridge, II : Irwin.

Tobing, E. 2005. Pendidikan dan Pertumbuhan Ekonomi. (Article online).Didapat dari http://www-theindone-sianinstitute.org/janeducfile.htm.Internet.

Todaro Michael P, 1985. Economic Development Report in the Third World. New York: Oxford University Press. 
Tjokrowinoto, M. 2001. Pembangunan Dilema dan Tantangan. Yogyakarta: Pustaka Pelajar.

Vitalaya, A., Prabowo T. dan Wahyudi R. 1995. Penyuluhan Pembangunan Indonesia: Menyongsong Abad XXI. Jakarta: PT Pustaka Pembangunan Swadaya Nusantara.

Woodward, J. 1965. Industrial Organization: Theory and Practice, Oxford University Press, Oxford. 